\title{
Detection of internal defects in CFRP composites by Eddy Current Thermography
}

\author{
by W. Swiderski*, P. Hlosta* \\ * Military Institute of Armament Technology, 7 Wyszynskiego Str., 05-220 Zielonka, Poland. \\ waldemar.swiderski@wp.pl
}

\begin{abstract}
The paper presents selected results of defect detection in a multilayer CFRP composite structure. The tests were carried out on a sample consisting of three plates made of CFRP connected with resin, in which the inner middle layer is made of four non-adherent elements. The method of Eddy Current Thermography (ECT) was used in the experimental testing. The results of these tests were then compared with the results obtained from numerical calculations..
\end{abstract}

\section{Introduction}

In recent years there has been a rapid development of non-destructive testing, especially methods of infrared thermography. Eddy current thermography is one of these methods and, as one of the non-destructive testing technologies, it has been used in many industries due to its high detection efficiency and non-contact method of measurement $[1,2,3]$. Eddy current thermography $[4,5,7]$ is a combination of thermographic and eddy currents involving the use of electromagnetic induction to create heat flow in a material and thereby register its thermal reaction using an infrared camera. The detection of defects is based on changes in thermal decomposition on the surface of the tested objects. An internal defect in the material hinders the local propagation of the heat wave generated by eddy currents, causing changes in the distribution of the temperature field on the surface of the tested material. Images (thermograms) recorded by the infrared camera enable localization of discontinuities (defects) of the internal structure of the test object. This technology is mainly used to test metals; however, it can also be used in non-destructive testing of composites. Electrically conductive composite samples can be heated by induction-eddy currents. The density of absorbed thermal radiation power is lower than in the case of heating with optical radiation sources; however, induction heating does not cause disturbances due to reflected radiation [8]. A material that meets the requirements of for use of the ECT method is a carbon fibre-reinforced plastic (CFRP) composite [9]. When building a multi-layer composite structure with a large surface area, it may be necessary to configure layers consisting of several thin plates manufactured in standard dimensions. During the performance of the multilayer structure, the plates in contact with each other may separate, creating gaps inside the composite structure and, thus, weakening its effectiveness.

\section{Numerical calculation}

Numerical calculations were made to assess the possibility of using ECT in detecting air-filled gaps with ThermoEdCur [10] computer software. ThermoEdCur software was developed by prof. Vavilova from the Tomsk University of Technology. The unique numerical algorithm used in ThermoEdCur, unlike many commercial programs available, allows modelling of very thin defects in relatively thick materials without loss of computational accuracy. Another unique feature of the program is that heating can be performed by a movable heat source, thereby modelling infrared thermography by creating eddy currents.

The ThermoEdCur program solves heat conduction equations using the numerical finite element method. The basis of the ThermoEdCur program development consists simulations of non-destructive testing processes, for which signals corresponding to transient states of surface temperature above subsurface defects are of fundamental importance. ThermoEdCur uses a unique algorithm that makes it possible to model very thin defects in thick materials without losing computational accuracy.

The program assumes that both the tested sample and subsurface defects have the shape of parallelepipeds. The thermal parameters of both the sample and any defects can be determined independently in all three planes of space, so that these elements can be fully anisotropically characterized. The model assumes that the side surfaces of the sample are adiabatically isolated. In contrast, temperature continuity is maintained between the boundaries of the sample layers and between any defects and their surroundings. The program also includes capacitive defects, which means that, unlike many other models used in non-destructive testing, both diffusivity and thermal conductivity of defects are included in the calculations. Thanks to this, a more accurate description of thermal phenomena related to the defect and its surroundings is possible.

In the case of heating with eddy currents, the stimulating thermal energy penetrates deeply, where the attenuation is described by the following formula $[10,11]$ 


$$
d Q=Q_{0} e^{\gamma \cdot d z}
$$

where $d Q$ is the energy absorbed within the $d z$ distance, and $\gamma$ is the eddy current absorption coefficient defined by:

$$
\gamma=\frac{\sqrt{\pi f \sigma \mu_{0} \mu}}{2}
$$

Here $f$ is the eddy current frequency, $\sigma$ is the electrical conductivity $[\mathrm{S} / \mathrm{m}], \mu_{0}=1.257 \cdot 10^{-6} \mathrm{~N} / \mathrm{m}$ is the magnetic permeability of free space $[\mathrm{H} / \mathrm{m}], \mu$ is the material relative magnetic permeability. Therefore, eddy current energy absorption is characterized by the following parameters: $f, \sigma, \mu$.

A linear heat source (Fig. 1) with an even distribution of energy begins to move along the surface of the sample, from the edge of the sample, at a constant speed $V$. The movement of the source can be made along any coordinate of the $X$ and $Y$ surfaces. In this case, the result of the calculation is a synthetic image in which each of the following lines is recorded at a constant distance from the rear surface of the tested object. Within the heat source with a moving line, even distribution of heat energy is assumed. The sample is only heated in a specific strip-like area. Other areas are cooled according to Newton's law.

Fig. 1 shows the principle of linear heating, which is often used in eddy-current heating to search the entire surface of the test object with even heating. Important parameters are the speed of heating line $\mathrm{V}$ and the width of line $\mathrm{S}$.

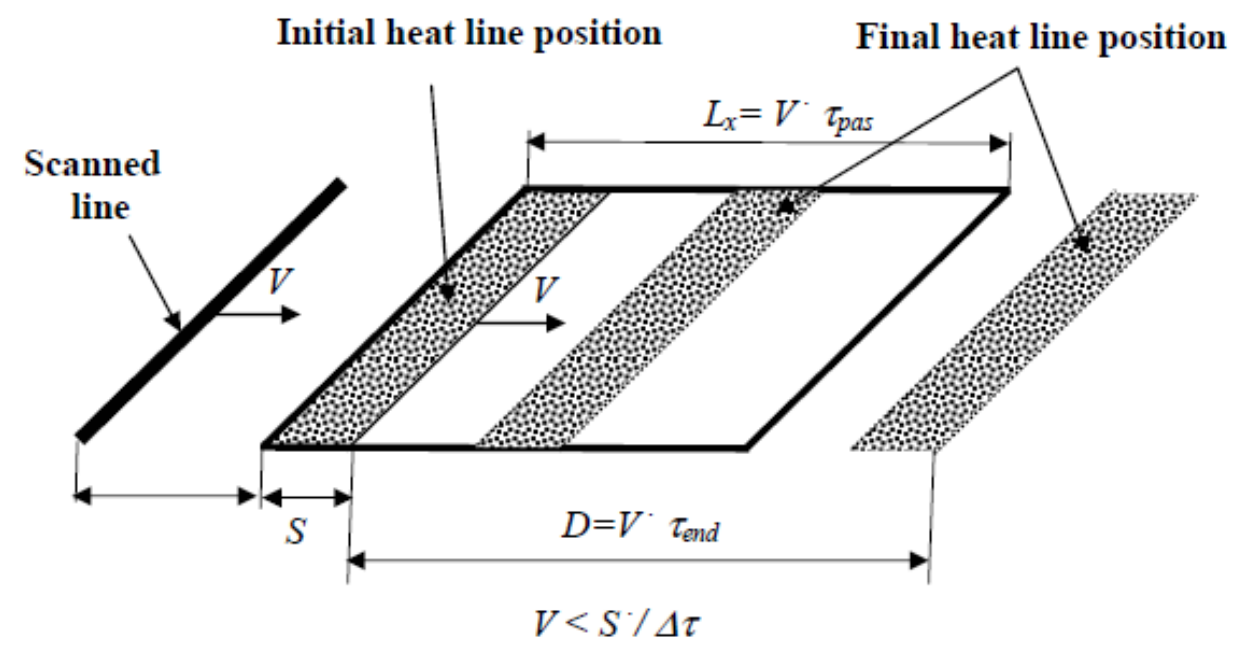

Fig. 1. Heating a sample with a heating line

A composite structure model consisting of three $0.9 \mathrm{~mm}$ thick carbon-fibre layers connected by $0.1 \mathrm{~mm}$ epoxy resin layers was tested. The total thickness of the tested model was $2.9 \mathrm{~mm}$, length $350 \mathrm{~mm}$, and width $150 \mathrm{~mm}$. The middle layer consisted of four elements between which there were three gaps D1 = 1, D2 = 2, and D3 = 5 mm wide (Fig.2). Table 1 shows thermal physical properties of materials used in model. Heating was simulated by a heating line moving along the model at a speed of $2 \mathrm{~cm}$ per second. Figure 3 shows the temperature field changes on the opposite side to the heat source of the sample being tested.

Table 1. Thermal physical properties of the sample and air $[7,12,13]$

\begin{tabular}{|l|l|l|}
\hline Properties & CFRP & Air \\
\hline Density $\left[\mathrm{kg} / \mathrm{m}^{3}\right]$ & 1500 & 1.3 \\
\hline Specific heat $[\mathrm{J} / \mathrm{kg} \cdot \mathrm{K}]$ & 846 & 1010 \\
\hline Thermal conductivity $[\mathrm{W} / \mathrm{m} \cdot \mathrm{K}]$ & $0.53(\perp)^{*}$ & 0.026 \\
& $2.33(\|)^{*}$ & \\
\hline Electrical conductivity $[\mathrm{S} / \mathrm{m}]$ & $3 \cdot 10^{5 *}$ & 0 \\
\hline Relative magnetic permeability & $1.26 \cdot 10^{-6}$ & 1 \\
\hline
\end{tabular}


*Values depend on a manufacturer and are supplied for orientation

** The electrical conductivity of the CFRP is anisotropic, as it is made up of electrically conductive carbon fibres embedded in the nonconductive resin.
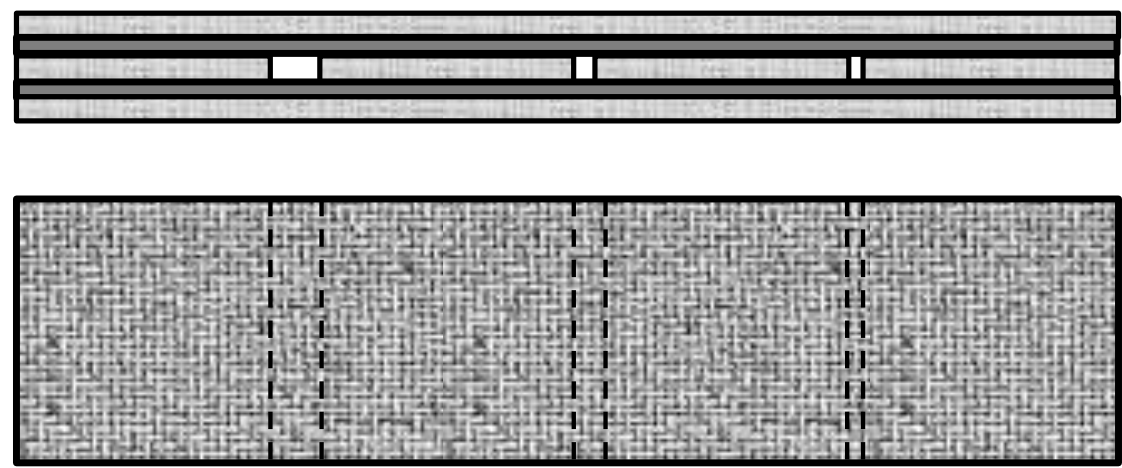

D1

D2

D3

Fig. 2. Model of sample.

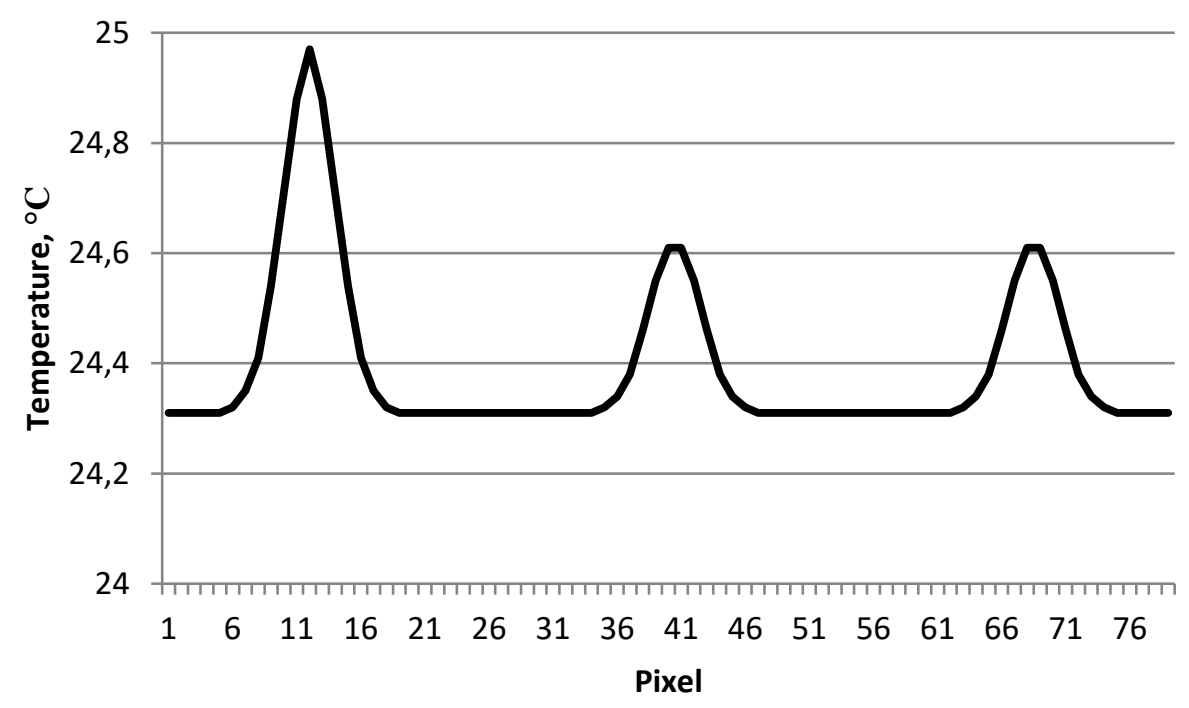

Fig. 3. Results of the simulation of eddy-current heating of a CFRP sample model.

\section{Experimental testing}

The experimental tests were carried out using the eddy current generator type EW030F from IFF companies [14]. Measurements and analysis were carried out using a FLIR SC-7600 thermal camera in conjunction with IrNDT software version 1.7.5.2 [15]. The generator head has the ability to move at a constant selected speed along the sample. The dimensions of the tested CFRP sample were the same as those used in the computer simulation. The tests were carried out by the transmission method, in which the camera and the head generating the eddy currents were on opposite sides of the tested sample. The set-up for experimental testing with eddy current IR thermography method is presented in Fig.4. The obtained results of changes in the temperature field on the surface of the tested sample are shown in Figure 5. 


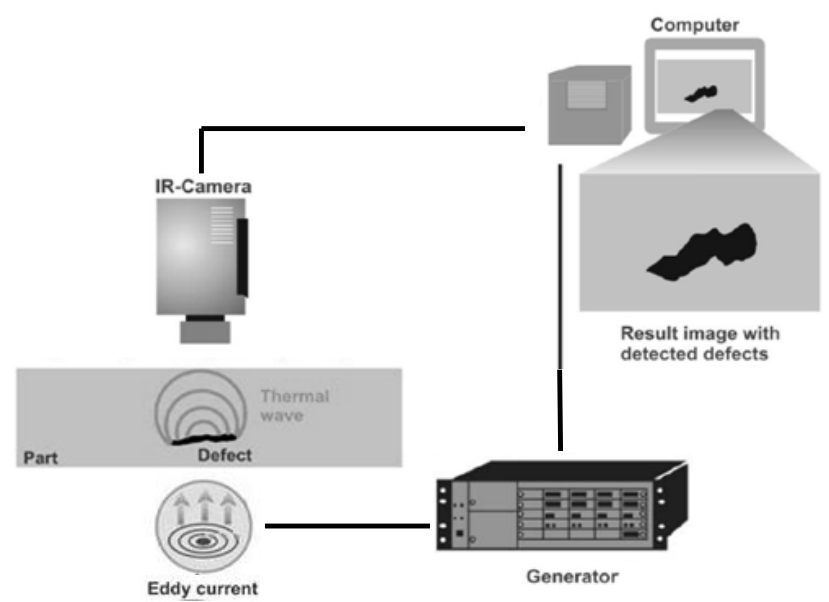

Fig. 4. Eddy current IR thermography - set-up

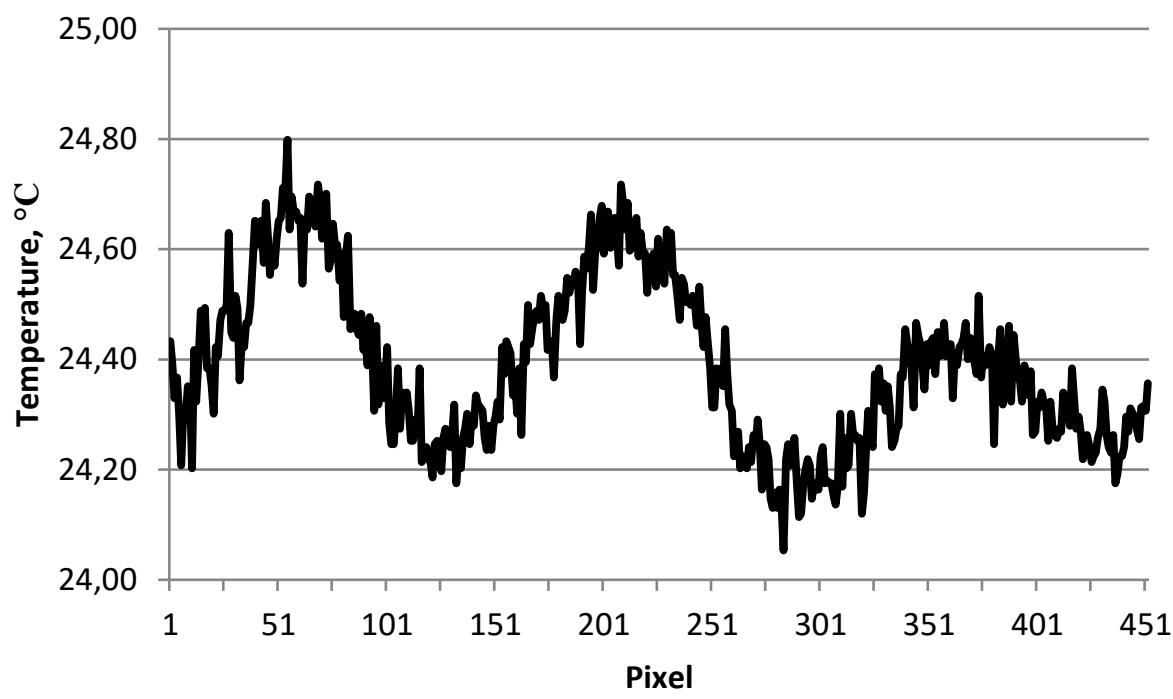

Fig. 5. Profile of temperature changes on the surface of the tested sample.

During further experimental tests, an additional $0.9 \mathrm{~mm}$ thick CFRP plate was glued to the tested sample from the unheated side using an epoxy resin layer approximately $0.1 \mathrm{~mm}$ thick. The thickness of the tested sample was 3.9 $\mathrm{mm}$. After these tests, another tile was glued from the unheated side, increasing the thickness of the test sample to 4.9 $\mathrm{mm}$. The obtained results of experimental tests are presented in Table 2.

Table 2. The results of experimental tests

\begin{tabular}{|l|l|l|l|}
\hline $\begin{array}{l}\text { The number of } \\
\text { CFRP layers }\end{array}$ & $\mathrm{D} 1 \Delta \mathrm{T}\left[{ }^{\circ} \mathrm{C}\right]$ & $\mathrm{D} 2 \Delta \mathrm{T}\left[{ }^{\circ} \mathrm{C}\right]$ & $\mathrm{D} 3 \Delta \mathrm{T}\left[{ }^{\circ} \mathrm{C}\right]$ \\
\hline 3 & 0.52 & 0.49 & 0.28 \\
\hline 4 & 0.39 & 0.37 & 0.19 \\
\hline 5 & 0.11 & 0.09 & 0.04 \\
\hline
\end{tabular}

\section{Summary}

The experimental tests confirmed the results obtained from computer simulation and the possibility of using ECT to detect defects in the form of air gaps in CFRP composites. The slight differences occurring are caused by the fact that the simplified model used in the computer simulation could not fully correspond to the real sample of the composite.

Experimental studies carried out on samples consisting of four and five layers of CFRP have shown that even a defect in the form of an air gap $1 \mathrm{~mm}$ wide can be detected in a sample consisting of 5 layers of CFRP. As can be seen 
from the results presented, the gap width for D2 and D3 defects has no significant effect on the value of the temperature signal over these defects. With a narrow gap (D1 defect), this difference is significant.

We plan that in our further work, we will better determine the possibilities and limitations of the ECT method in CFRP composite testing.

\section{REFERENCES}

[1] Gao B., Li X., Woo W. L., et al., Quantitative validation of Eddy current stimulated thermal features on surface crack, NDT\&E Int. 85: pp. 1-12, 2017.

[2] Ruwandi Fernando W. D., Tantrigoda D. A., Rosa S. R. D., et al., Infrared thermography as a non-destructive testing method for adhesively bonded textile structures, Infrared Phys. Technol. 98: pp. 89-93, 2019.

[3] He M., Li W., Zhang Y., Zheng W., Research on temperature distribution low around crack using the moving mode of eddy current thermography, Infrared Physics\&Technology, Vol. 102, 10293, 2019.

[4] Oswald-Tranta B., Walle G., Oswald J., A semi-analytical model for the temperature distribution of thermo inductive heating, Proceedings of 8th Quantitative InfraRed Thermography conference, Padova ( Italy), 2006

[5] Maldague X. P., Introduction to NDT by active infrared thermography, Mater. Eval., Vol. 60, no 9, pp. 1060 1073, 2002

[6] Taram A., Roquelet C., Anderhuber M., Meilland P., Mouhoubi K., Bodnar J. L., Detection of Subsurface Defects in Steels using Pulsed Eddy Current Thermography, $13^{\text {th }}$ International Conference on : Quantitative Infrared Thermography, pp. 832-839, Gdansk (Poland), 2016

[7] Swiderski W., Thermographic methods in non-destructive testing of composite materials for special applications. WITU, Zielonka, 2010 (in Polish)

[8] Świderski W., Detecting defects in marine structures by using eddy current infrared thermography, Applied Optics, Vol. 55, Issue 34, pp. D17-D21, 2016

[9] Mook G, Lange R, Koeser O. Non-destructive characterisation of carbon-fibre reinforced plastics by means of eddy-currents. Compos Sci Technol, 61(6): pp. 865-73, 2001.

[10] ThermoEdCur - Operational Manual. The software for computing 3D dynamic temperature distributions in anisotropic solid heated with motionless and moving heat sources. Russia, Tomsk 2014.

[11] Swiderski W., Hlosta P., Evaluation of Paint Coating on Metal Elements Using Scanning Pulsed Eddy Current Thermography, 14 ${ }^{\text {th }}$ QIRT Conference, Book Series: Quantitative Infrared Thermography, pp.556-562, 2018

[12] Swiderski W., Non-destructive Testing of Composite Materials Used in Military Applications by Eddy Current

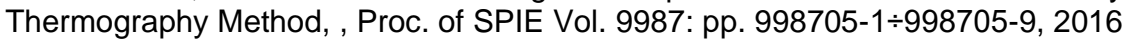

[13] Li Z., Meng Z., A Review of the Radio Frequency Non-destructive Testing for Carbon-fibre Composites, Measurement Science Review, 16, no. 2: pp. 68-76, 2016

[14] www.iff-gmbh.de

[15] www. automationtechnology.de 